\title{
Diopatra neapolitana (Polychaeta: Onuphidae) as a Second Intermediate Host of Gymnophallus choledochus (Digenea: Gymnophallidae) in the Aveiro Estuary (Portugal): Distribution Within the Host and Histopathology
}

L. F. Rangel and M. J. Santos*, Universidade do Porto, Faculdade de Ciências, Departamento de Zoologia-Antropologia, Rua do Campo Alegre, s/n, FC4, 4169-007 Porto, Portugal; CIMAR Laboratório Associado/CIIMAR, Centro Interdisciplinar de Investigação Marinha e Ambiental, Universidade do Porto, Rua dos Bragas, 289, 4050-123 Porto, Portugal; *To whom correspondence should be addressed. e-mail: mjsantos@fc. up.pt

ABSTRACT: This is the first host record of Gymnophallus choledochus metacercariae infecting the polychaete Diopatra neapolitana in the Aveiro estuary (Portugal). The metacercariae were found unencysted, and their morphology is similar to that presented by metacercariae harbored by Nereis diversicolor and Cerastoderma edule, although they are larger in size. In $D$. neapolitana, the prevalence and mean intensity of the infection was very high, at $100 \%$ and $202 \pm 139$ metacercariae per host, respectively, suggesting that this polychaete is the most suitable host for G. choledochus in the Aveiro estuary. In terms of distribution within the host, the metacercariae were found almost exclusively in the branchial segments (97.4\%). This, in conjunction with the close relationship between the mean intensity and branchial surface area, suggests that the branchiae may be the site of entry into the polychaete. Within the branchial segments, the sites selected by the metacercariae are the parapodia (68.9\%), where they are mostly located inside the setal sac, and the longitudinal muscles $(22.3 \%)$, causing hypertrophy and rupture of the muscle bundles, respectively. These histological changes suggest a reduction in polychaete mobility, which should aid the easy predation of infected hosts by birds and thus facilitate the continuity of the $G$. choledochus life cycle.

Gymnophallus choledochus Odhner, 1900, is a small, gymnophallid digenean that uses charadriiform, lariform, and anatid birds as the definitive host (Loos-Frank, 1969; Bartoli, 1974a). The first intermediate hosts of $G$. choledochus are bivalves, such as Cerastoderma edule (Linnaeus, 1758) (Loos-Frank, 1969; Russel-Pinto, 1993) and Cerastoderma glaucum (Poiret, 1789) (Bartoli, 1974a). The second intermediate hosts are polychaetes, including Nereis diversicolor O.F. Müller, 1776 (Prévot, 1965; Loos-Frank, 1969; Bartoli, 1974a; Russel-Pinto, 1993), Nephthys hombergi Savigny in Lamarck, 1818, and Arenicola spp. (LoosFrank, 1969). According to the latter author, the life cycle of $G$. choledochus in the North Sea follows 2 pathways, depending on the

DOI: 10.1645/GE-2015.1 season of the year. In spring and summer, the metacercariae use polychaetes as second intermediate hosts. In autumn and winter, because of the low temperatures in the North Sea, polychaetes are not involved; during these months, $C$. edule also serves as the second intermediate host. In the Aveiro estuary (Portugal), metacercariae of G. choledochus occur throughout the year inside sporocysts within $C$. edule, suggesting an evolutionary suppression of the second intermediate host ( $N$. diversicolor) from the life cycle (Russel-Pinto, 1993; Russel-Pinto et al., 2006).

The prevalence and mean intensity values for G. choledochus were generally low, i.e., $1.6 \%$ and 3.0 worms, respectively, in $N$. diversicolor, and around $2 \%$ of prevalence in sporocysts of C. edule, in the Aveiro estuary (Russel-Pinto, 1993). In the North Sea, prevalence ranged from 0.8 to $7.0 \%$ (with the sporocyst stage included) for C. edule, with 1-8 metacercariae inside each sporocyst (Loos-Frank, 1969).

In $N$. diversicolor, the metacercariae of $G$. choledochus occur inside the setal sac in the parapodia, causing hypertrophy (Bartoli, 1974a, 1974b; Russel-Pinto, 1993). When observed in C. edule, the metacercariae were found inside the sporocysts and do not initiate any direct response from the mollusk. However, the sporocyst does cause tissue destruction, mainly in the gonads (Russel-Pinto, 1993). Another report of Gymnophallus sp. in the mytilid Modiolus barbatus confirmed this finding, indicating that its sporocysts induce a retardation of gametogenesis, necrosis of the connective tissue, and hemocytic infiltration (Mladineo and Peharda, 2005).

The morphology of G. choledochus metacercariae hosted by $N$. diversicolor, collected in different locations (Mediterranean and North Sea) is generally similar, with just a few differences in the size of the body (Loos-Frank, 1969; Bartoli, 1974a). However, metacercariae occurring in sporocysts within $C$. edule are usually much smaller when compared with metacercariae harbored by $N$. diversicolor (Loos-Frank, 1969) (Table I).

Diopatra polychaetes are tubiculous species found in all of the main oceans, with a distribution ranging from the intertidal zone to demersal depths (Paxton, 1986). Diopatra neapolitana (Delle Chiaje, 1841) is a benthic species common in the Aveiro estuary, where it is found inside buried tubes on muddy sediment between 0 and $4 \mathrm{~m}$ in depth; it is

TABLE I. Gymnophallus choledochus metacercaria measurements (in micrometers) from Diopatra neapolitana compared with metacercaria from Nereis diversicolor and Cerastoderma edule sporocyst presented by other authors ( $\mathrm{SD}=$ standard deviation).

\begin{tabular}{|c|c|c|c|c|c|c|c|c|c|}
\hline & \multicolumn{9}{|c|}{ Host } \\
\hline Body length & $232-255$ & 241 & $282-326$ & 308 & $240-306$ & 280 & $293-500$ & 410 & 49.7 \\
\hline Body width & $97-101$ & 99 & $128-151$ & 137 & $125-180$ & 147 & $120-227$ & 164 & 36.5 \\
\hline Oral sucker length (O.S.) & $42-44$ & 43 & $60-67$ & 63 & $51-65$ & 57 & $65-91$ & 80 & 5.9 \\
\hline Ventral sucker width & - & - & - & - & $48-62$ & 56 & $63-96$ & 75 & 8.1 \\
\hline Ratio O.S./V.S. & - & 1.1 & - & 1.1 & $1.0-1.2$ & 1.1 & $0.9-1.3$ & 1.1 & 0.1 \\
\hline Pharynx length (P.) & $22-24$ & 23 & $24-30$ & 27 & $19-24$ & 22 & $27-39$ & 32 & 3.5 \\
\hline Pharynx width & $20-33$ & 28 & $33-40$ & 38 & $23-31$ & 26 & $23-44$ & 31 & 5.5 \\
\hline Ratio O.S./P. & - & 1.9 & - & 2.3 & $2.3-2.8$ & 2.6 & $1.7-3.3$ & 2.5 & 0.3 \\
\hline Forebody length & - & - & - & - & $133-192$ & 167 & $166-293$ & 229 & 30.3 \\
\hline
\end{tabular}




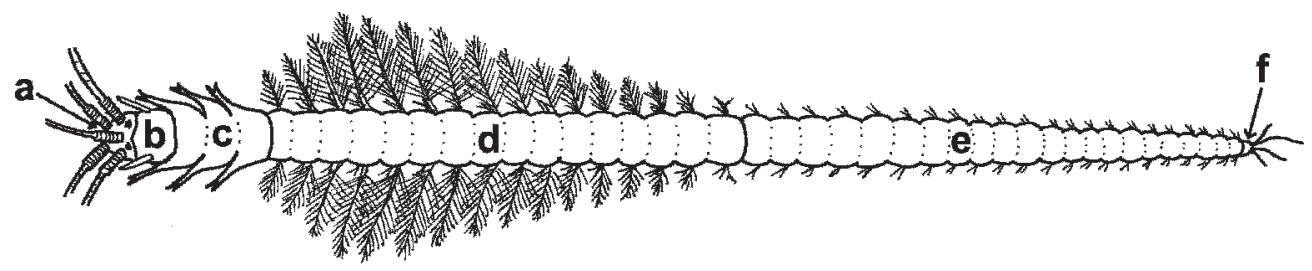

Figure 1. Morphology of Diopatra neapolitana. (a) prostomium; (b) peristomium; (c) segments with modified parapodia; (d) segments with parapodia bearing branchiae (branchial segments); (e) posterior segments without branchiae (post-branchial segments); (f) pygidium.

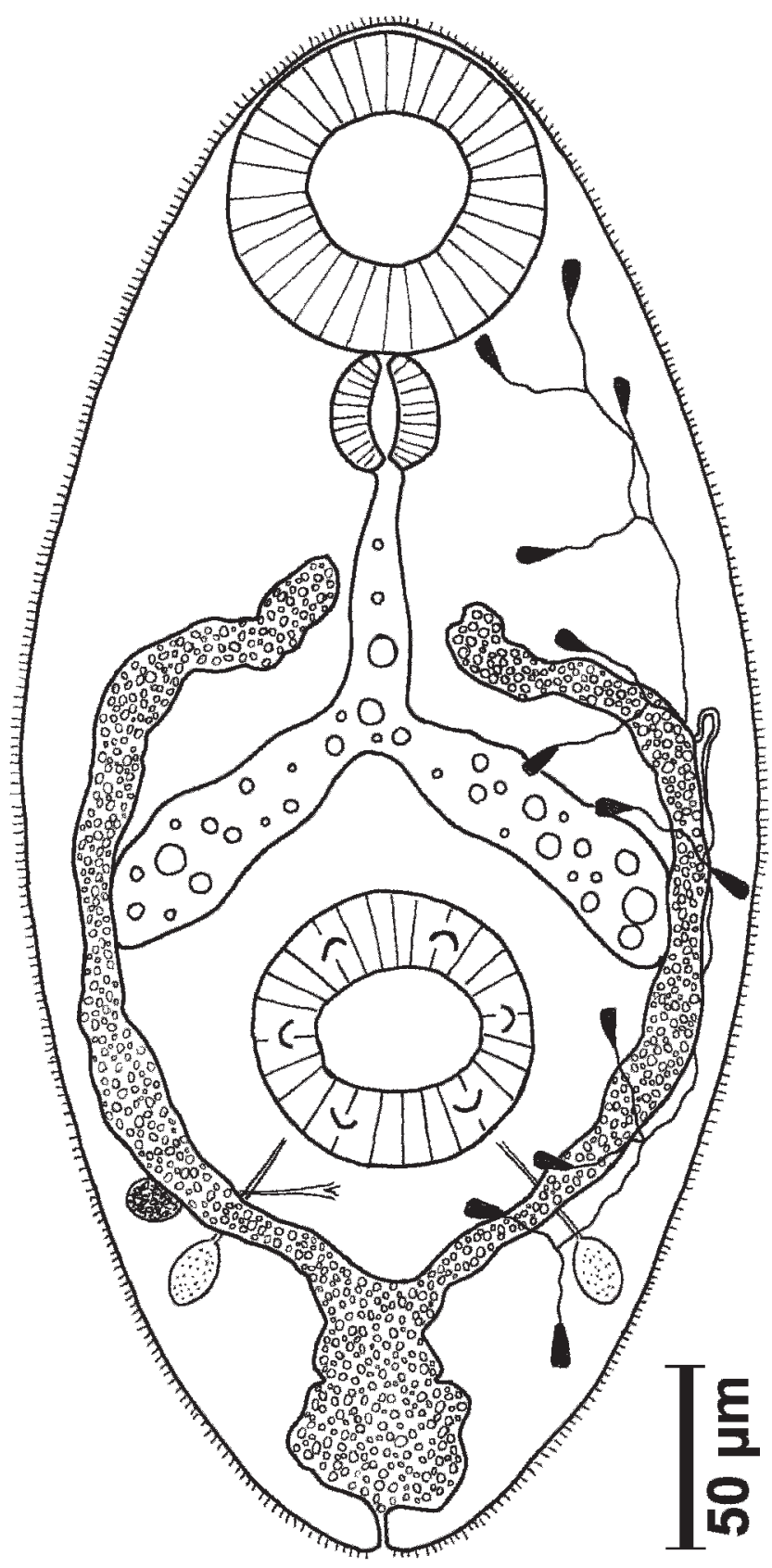

FIGURE 2. Drawing of Gymnophallus choledochus metacercariae from Diopatra neapolitana. commercially exploited as bait for anglers (Cunha et al., 2005). According to the latter authors, its density in the Mira Channel (a branch of the Aveiro estuary) was estimated to be around 3 individuals $/ \mathrm{m}^{2}$.

The main aim of this paper is to present the first host record of $G$. choledochus in D. neapolitana and to report on its distribution within the host, its histopathology, and its morphology in this new host.

Specimens of $D$. neapolitana were collected by bait diggers in the Aveiro estuary, Portugal $\left(40^{\circ} 40^{\prime} \mathrm{N}, 8^{\circ} 45^{\prime} \mathrm{W}\right)$. The polychaetes were retained inside their tubes, wrapped in sheets of newspaper, and kept under refrigeration at 5-8 C. Under these conditions, they survive for several days. For the parasitological examination, the polychaete was removed from its tube. However, since the capture technique used by bait diggers cuts part of its body and only the anterior portion of the polychaete is recovered, only those specimens that had an anterior body portion with a prostomium, peristomium, modified parapodia segments, branchial segments, and several post-branchial segments were inspected (Fig. 1). The polychaetes were sexed by the examination of gametes collected from the coelomic fluid in the post-branchial segments. The prevalence (Bush et al., 1997) of G. choledochus was determined in 186 specimens of D. neapolitana (89 females, 78 males, and 19 undetermined sex), collected monthly, from October 2006 to September 2007.

To examine metacercariae distribution within the host, the infection sites in 15 randomly selected specimens of $D$. neapolitana ( 8 males and 7 females) were investigated. For every specimen, each segment was dissected and inspected individually; the intensity of metacercariae (Bush et al., 1997) was determined; and their site within the segment was recorded.

To establish whether the branchiae might be the entry site of $G$. choledochus, we compared the mean intensity of the parasite per segment with the mean available branchial surface area. The branchiae of $D$. neapolitana are composed of filaments attached spirally around a central trunk. More turns of the branchial filaments represent greater surface area. Thus, to give a measurement of the surface area, the number of turns of the branchial filaments was recorded for each branchial segment in 15 randomly selected specimens.

To analyze any histopathology caused by $G$. choledochus, a branchial segment of a single specimen of $D$. neapolitana presenting a high intensity of infection was processed and stained with hematoxylin and eosin (H\&E).

For the morphological examination of G. choledochus, 29 metacercariae were isolated, fixed, preserved in $70 \%$ ethanol, and later stained with ironacetocarmine (Georgiev et al., 1986). These metacercariae were identified at the generic level as Gymnophallus according to Scholz (2002) and James (1964) and at the species level as G. choledochus Odhner, 1900, using with the metacercariae descriptions of Loos-Frank (1969) and Bartoli (1974a). Measurements were made using stained worms, slightly compressed with a coverslip (as described by Bartoli, 1974a), and mounted in Canada balsam. All measurements include the mean \pm the standard deviation. The parasites were examined and photographed using a Zeiss Axiophot microscope (Grupo Taper, Sintra, Portugal), equipped with a Zeiss Axiocam Icc3 digital camera. Axiovision 4.6 software (Grupo Taper) was used for the image analysis. A drawing of G. choledochus was prepared from several photographs, taken at different levels of focus.

Gymnophallus choledochus occur in D. neapolitana as unencysted metacercariae (Fig. 2, Table I). The prevalence of G. choledochus was $100 \%(\mathrm{n}=186)$, and the mean \pm standard deviation intensity of infection was $202 \pm 139$ (range: $1-451)$ metacercariae per host. Female hosts $(n=7)$ 


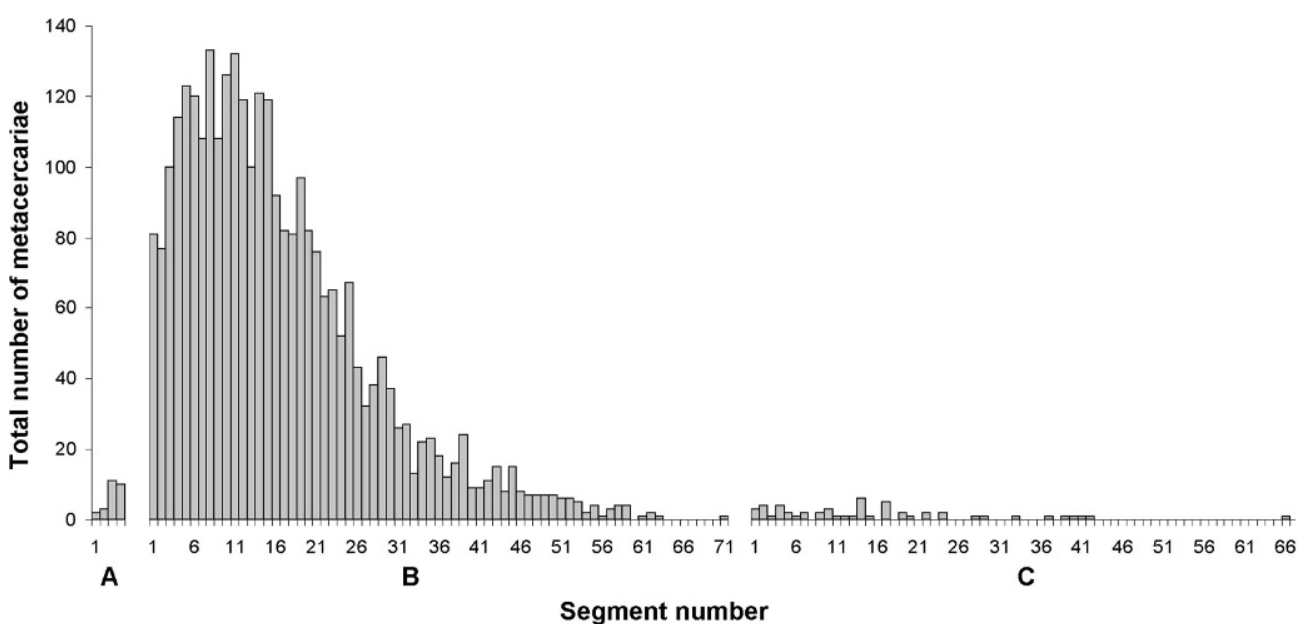

FIGURE 3. Distribution of Gymnophallus choledochus metacercariae within the body segments of Diopatra neapolitana. (A) segments with modified parapodia; (B) branchial segments; (C) Post-branchial segments.

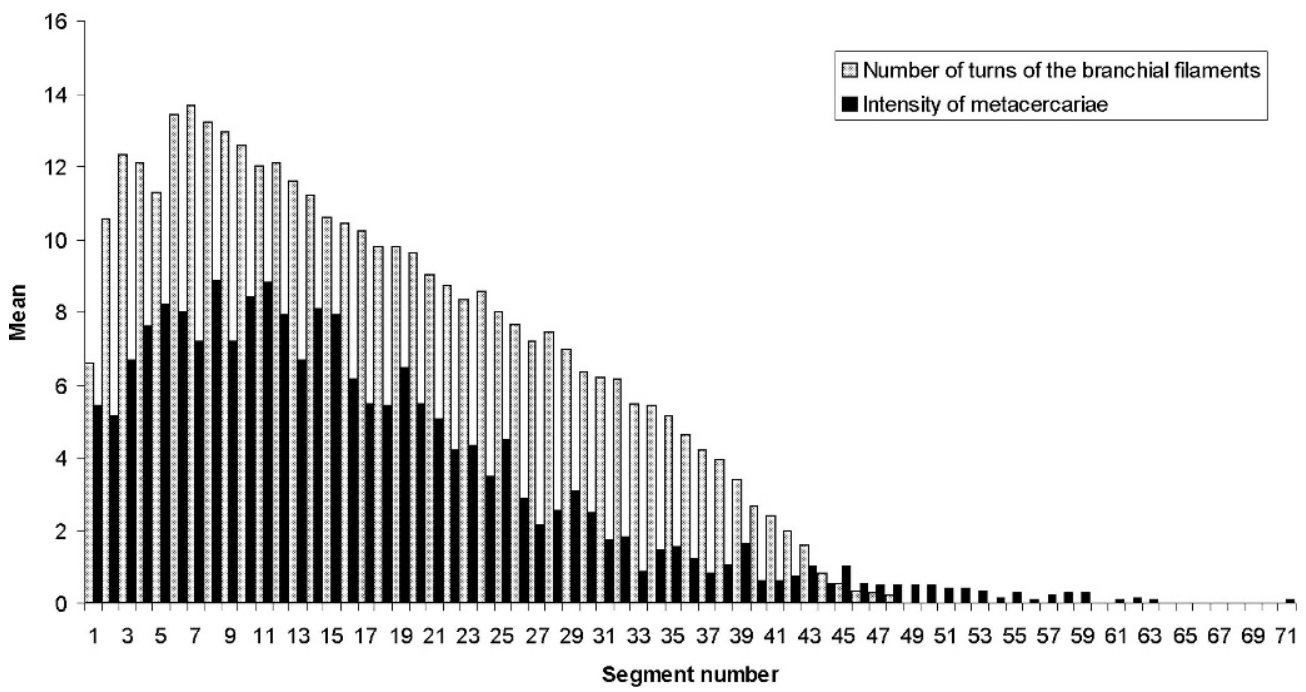

Figure 4. Variation of the mean intensity of infection of Gymnophallus choledochus metacercariae and mean number of turns of the branchial filaments of Diopatra neapolitana along the branchial segments.

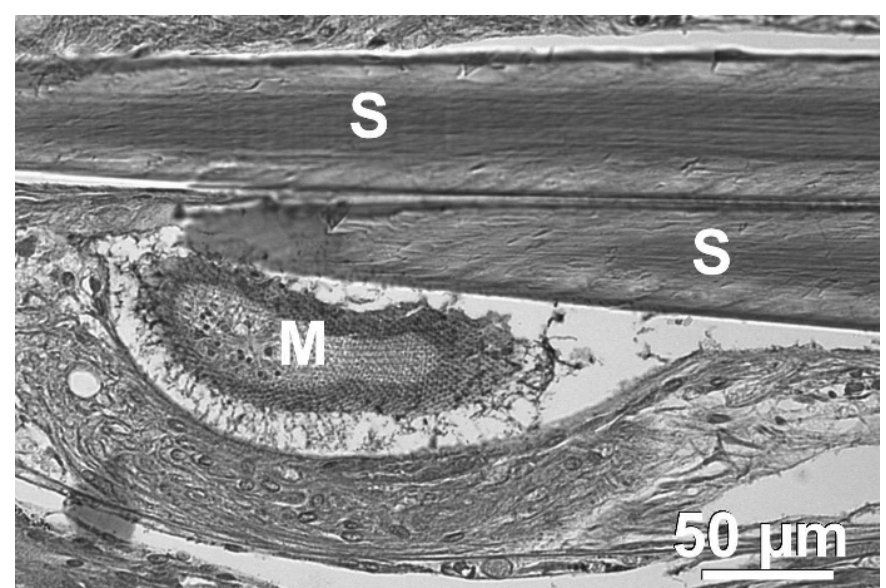

Figure 5. Histological cross-section of the parapodial region of Diopatra neapolitana, showing a single metacercariae inside the hypertrophied setal sac. S, setae; M, metacercariae. H\&E stain.

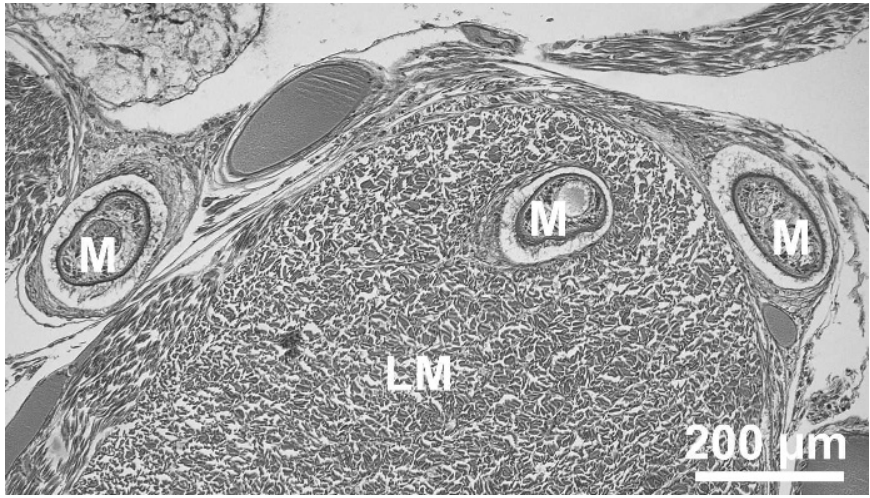

Figure 6. Histological cross-section of the longitudinal muscles of Diopatra neapolitana, showing 3 metacercariae enclosed by a thin sheet of connective tissue and ruptured muscle bundles. LM, longitudinal muscles; $\mathrm{M}$, metacercariae. H\&E stain. 
had a mean intensity of $239 \pm 125$, with $168 \pm 150$ metacercariae in males $(\mathrm{n}=8)$.

The body of $D$. neapolitana is composed of a prostomium, bearing the antennae and palps, a peristomium, 3 or 4 segments with modified parapodia, 45-71 segments with parapodia bearing spiral branchiae (branchial segments), several posterior segments with parapodia without branchiae (post-branchial segments), and finally the pygidium with anal cirri (Fig. 1). Metacercariae of G. choledochus were found almost exclusively in the branchial segments $(97.4 \%, \mathrm{n}=3,037$ metacercariae in the 15 hosts) (Fig. 3). The few remaining metacercariae were found in segments with modified parapodia $(0.9 \%)$ and in the initial post-branchial segments $(1.7 \%)$. We found a close association between the branchial surface area in each segment and the mean intensity of infection on those branchial segments (Fig. 4). The first 20 branchiae (28\%) possessed the maximum number of filament turns; these segments also harbored $70 \%$ of the total metacercariae.

The distribution of metacercariae inside each segment was as follows: $68.9 \%$ were located in the parapodia, $22.3 \%$ in the longitudinal muscles and the remaining $8.9 \%$ in the coelomic spaces, blood vessel areas, and muscles surrounding the intestine. In the parapodia, metacercariae were found in association with the setae and, usually, inside the setal sac (Fig. 5). In the longitudinal muscles, they were located inside the muscle bundles, although some were peripheral (Fig. 6). The maximum number of metacercariae found in both parapodia of a single segment was 54 whereas in the longitudinal muscles this number was 22 . The greatest intensity in a single segment reached 78 metacercariae.

The histopathology involved replacement of host tissues by metacercariae, which were conspicuous in muscle tissue, causing muscle bundles to rupture and the formation of a thin sheet of connective tissue around the parasite (Figs. 5, 6). Frequently, 4-9 metacercariae were observed inside a single setal sac, resulting in its hypertrophy.

This is the first record of the metacercariae of G. choledochus infecting the polychaete $D$. neapolitana, although not the first report of this parasite using a polychaete as its second intermediate host (Prévot, 1965; LoosFrank, 1969; Bartoli, 1974a). Even the morphology of these metacercariae in this host is very similar, apart from its larger size, to that previously reported. What distinguishes observations in the present study are the high prevalences and infection intensities seen here, i.e., 100\% and 202 metacercariae per host, respectively. If we consider that $D$. neapolitana and $N$. diversicolor are 2 very common polychaete species in the Aveiro estuary, we might reasonably expect a similar prevalence of infection in both polychaetes if they are equally susceptible to the parasite. However, the prevalence of $G$. choledochus has been reported at only at $1.6 \%(\mathrm{n}=$ 189 ) in $N$. diversicolor (see Russel-Pinto, 1993), which caused the latter authors to propose a secondary suppression of polychaetes from the life cycle, once metacercariae were able to develop within sporocysts in $C$. edule (besides its low infection level). In view of the present findings, $G$. choledochus uses the polychaete $D$. neapolitana as the most suitable second intermediate host in the Aveiro estuary.

Both polychaetes, $N$. diversicolor and $D$. neapolitana, are benthic species living buried in the sediments in galleries and tubes, respectively. Bartoli (1974a) noted that $N$. diversicolor naturally infected by Meiogymnophalus nereicola, showed a distribution pattern of the parasite within the host dependent on the distance to their gallery opening. Thus, he observed a greater intensity of infection in the anterior segments, closer to the gallery opening, and a constant decline toward the posterior segments. Comparing this distribution pattern with the one we found in $D$. neapolitana, naturally infected by G. choledochus, we concluded that the same pattern is not followed in both hosts. Instead, a strong relationship with the branchial surface area was seen (Fig. 4). Moreover, the metacercariae were almost absent in post-branchial segments. These observations led us to the conclusion that G. choledochus cercariae probably penetrate $D$. neapolitana through the branchiae.
The majority of the G. choledochus metacercariae were found inside the setal sac, in the parapodial region of $D$. neapolitana. This site coincides with the one previously reported in $N$. diversicolor (Bartoli, 1974a, 1974b) Nevertheless, in the presently studied host, the parasite expanded the infection to the muscle bundles. This seems to be due to the large area available by this host's strong musculature, consisting of 4 large longitudinal muscle bundles.

The presence of metacercariae in these infection sites, causing hyperplasia of the setal sacs and muscle rupture, suggests a limitation of the infected polychaetes' mobility. This then increases their relative vulnerability to the predation by aquatic birds, the definitive hosts of $G$. choledochus.

This study was financed by CIIMAR-Pluriannual Program. The authors would like to thank 3 anonymous referees for their valuable comments and Dr. David Gibson for his help with the English.

\section{LITERATURE CITED}

BARToli, P. 1974a. Recherches sur les Gymnophallidae F. N. Morozov, 1955 (Digenea), parasites d'Oiseaux des côtes de Camargue: systématique, biologie et écologie. PhD Thesis. Université de droit, d'economie et des sciences d'Aix-Marseille, Marseille, France, 338 p.

1974b. Un cas d'exclusion compétitive chez les trématodes: l'élimination de Gymnophallus choledochus T. Odhner, 1900 par G. nereicola Rebecq et G. Prévot, 1962 en Camargue (France) (Digenea, Gymnophallidae). Bulletin de la Société Zoologique de France 99: $551-559$.

Bush, A. O., K. D. Lafferty, J. M. Loft, and A. W. Shostak. 1997. Parasitology meets ecology on its own terms: Margolis et al. revisited. Journal of Parasitology 83: 575-583.

Cunha, T., A. Hall, and H. Queiroga. 2005. Estimation of the Diopatra neapolitana annual harvest resulting from digging activity in Canal de Mira, Ria de Aveiro. Fisheries Research 76: 56-66.

Georgiev, B. B., V. Biserkov, And T. Genov. 1986. In toto staining method for cestodes with iron acetocarmine. Helminthologia 23: 279281.

James, B.L. 1964. The life cycle of Parvatrema homoeotecnum sp. nov. (Trematoda: Digenea) and a review of the family Gymnophallidae Morozov, 1955. Parasitology 54: 1-41.

Loos-Frank, B. 1969. Zur Kenntnis der gymnophalliden Trematoden des Nordseeraumes I. Die Alternativ-Zyklen von Gymnophallus choledochus Odhner, 1900. Zeitschrift für Parasitenkunde 32: 135-156.

Mladineo, I., And M. Peharda. 2005. Histopathology of Gymnophallus sp. sporocysts in the edible mytilid, Modiolus barbatus. Journal of Shellfish Research 24: 1097-1100.

Paxton, H. 1986. Generic revision and relationships of the family Onuphidae (Annelida: Polychaeta). Records of the Australian Museum 38: 1-74.

Prévot, G. 1965. Développement expérimental d'une métacercaire de Gymnophallus (Trematoda: Digenea). Bulletin de la Société Zoologique de France 90: 451-456.

Russel-Pinto, F. 1993. Espécies de Digenea que infectam Cerastoderma edule (n.v. berbigão) em Portugal. Caracterização da resposta do hospedeiro à infestação. Ph.D. Thesis. Instituto de Ciências Biomédicas Abel Salazar, University of Porto, Porto, Portugal, 247 p.

, J. F. Gonçalves, and E. Bowers. 2006. Digenean larvae parasitizing Cerastoderma edule (Bivalvia) and Nassarius reticulatus (Gastropoda) from Ria de Aveiro, Portugal. Journal of Parasitology 92: 319-332.

Scholz, T. 2002. Family Gymnophallidae Odhner, 1905. In Keys to the Trematoda (Vol. 1), D.I. Gibson, A. Jones, AND R.A. Bray (eds.). CAB International, Wallingford, U.K., p. 245 251. 